\title{
Proposing Major BRT Routes for Rajshahi City Towards Increasing Public Transport Demand and Alleviation of Congestion Level to Achieve A Sustainable Urban Public Transport System
}

\author{
Pankaj Kanti Jodder ${ }^{1, *}$, Emon Kabir Noyon ${ }^{2}$, Salman Bashit ${ }^{1}$, Muhaiminul Islam ${ }^{1}$ \\ ${ }^{1}$ Urban and Rural Planning Discipline, Khulna University, Khulna, Bangladesh \\ ${ }^{2}$ Asian Disaster Preparedness Center (ADPC), Rajshahi, Bangladesh \\ Email address: \\ pankajkantijodder@gmail.com (P. K. Jodder) \\ ${ }^{*}$ Corresponding author
}

\section{To cite this article:}

Pankaj Kanti Jodder, Emon Kabir Noyon, Salman Bashit, Muhaiminul Islam. Proposing Major BRT Routes for Rajshahi City Towards Increasing Public Transport Demand and Alleviation of Congestion Level to Achieve A Sustainable Urban Public Transport System. American Journal of Engineering and Technology Management. Vol. 5, No. 4, 2020, pp. 61-68. doi: 10.11648/j.ajetm.20200504.11

Received: January 17, 2020; Accepted: February 12, 2020; Published: July 6, 2020

\begin{abstract}
Rajshahi is the fourth largest city of Bangladesh having a population of around 8 lakhs with a high urbanization rate of $32.93 \%$. The transportation system of Rajshahi is comprising of motorized transport (bus, mini-bus, truck, car, autorickshaw, auto-tempo, motorcycle, etc.) and nonmotorized transports (viz. rickshaw, rickshaw van, bicycle, pushcart, etc.). The rapidly increasing population along with the diversified land-use patterns generating considerable transport demands on the transportation system and the higher number of transport vehicles causes numerous problems in the city such as traffic congestion, road accidents, less effective and inefficient traffic movement, inadequate traffic management, environmental pollution, sound pollution and so on. The number of private vehicles is increasing day by day because there is no public transport system with an effective public transport network within the city. As a result, major shares of the roads are occupied by the small vehicles make complexities for efficient traffic movement. According to a recent analysis of RCC (Rajshahi City Corporation) the annual average growth rate of these traffics is motorized $(8.50 \%)$, auto-rickshaw $(12.30 \%)$, motorcycle $(12.60 \%)$, truck $(5.30 \%)$ and car $(5.70 \%)$. So, the upcoming future of the transport sector in Rajshahi city is going to face an uncertain challenge through the increasing population and rapidly growing motorized traffics which will affect the efficiency and effectiveness of the transport systems. In view of the worsening traffic congestion and deterioration inaccessibility, level of service, safety, and operational efficiency, it is time to introduce the Bus Rapid Transit (BRT). In this paper, an attempt has been made to provide an overview of the public transportation system of Rajshahi city and five major BRT routes have been proposed for ever-increasing public transport demand towards alleviation of congestion level and achieving a sustainable urban public transport system.
\end{abstract}

Keywords: Traffic Congestion, Bus Rapid Transit, Sustainable Traffic System, GIS, Rajshahi City

\section{Introduction}

Rajshahi is a major urban, commercial and educational center of Bangladesh holding $96.72 \mathrm{~km}$ with a high urbanization rate of $32.93 \%$. Geographically Rajshahi is situated within $24^{\circ} 22^{\prime} 26^{\prime \prime} \mathrm{N}$ and $88^{\circ} 36^{\prime} 04^{\prime \prime} \mathrm{E}$. The total population of Rajshahi city corporation is 449750 including 30 wards with 174 mahalla (BBS 2011) [1]. In very recent time WHO (World Health Organization) announces Rajshahi, as the most "Air pollution less" city in the world in 2016. People from the surrounding districts around Rajshahi come to live here as this is the most livable city among all the cities in Bangladesh. Throughout the city, the population rate is increasing day by day. As the rate was increased by $1.52 \%$ in 
2017 which has been increased as $1.48 \%$ in 2019 and it is forecasted that in the year of 2030 the population growth rate should rise up to $2.43 \%$ [2]. The gradual increase of the population makes many commercial or recreational hubs throughout the city such as Shaheb Bazar, Zero Point, Lokkhipur, Bornali Mor, Bindur Mor, Station Mor, Vodra Mor, C\&B Mor and so on. The city is expanding with high population growth and high vehicular demands through the rapid urbanization process. As a result, the transportation system of the city faces complexities with inadequate transportation facilities and policies, varied traffic mix with over-concentration of nonmotorized vehicles, absence of dependable public transport system and inadequate traffic management practices. Traffic congestion in major intersections, market places and CBD areas is a common thing in Rajshahi city which affects the efficiency and effectiveness of the overall transportation system. The continue traffic congestion resulting in major problem. The greater challenge thus for transportation to develop a sustainable traffic system to meet the mobility needs of urban people with a convenient traffic system avoiding the unacceptable level of congestion [3].

In many countries, Bus Rapid Transit (BRT) has been proved as an emerging solution as well as a cost-effective way of addressing urban congestion [4]. So, it has been indicated that BRT is an effective alternative for congested cities at relatively low construction and operational cost. For this reason, a sound public transport route should be proposed in the Master Plan of Rajshahi. In this paper, it should be tried to introduce the key transport and traffic characteristics in metro Rajshahi metropolitan area and to speculate the significance of introducing BRT in Rajshahi metro city to meet up the increasing public transport demand proceeding to alleviate the congestion level and to accomplish a sustainable urban public transport system.

Objective to develop BRT for Rajshahi is to-

a) Identify the possible public bus transit route for the Rajshahi city corporation.

b) Define the area coverage by the public bus transit and bus stoppage points.

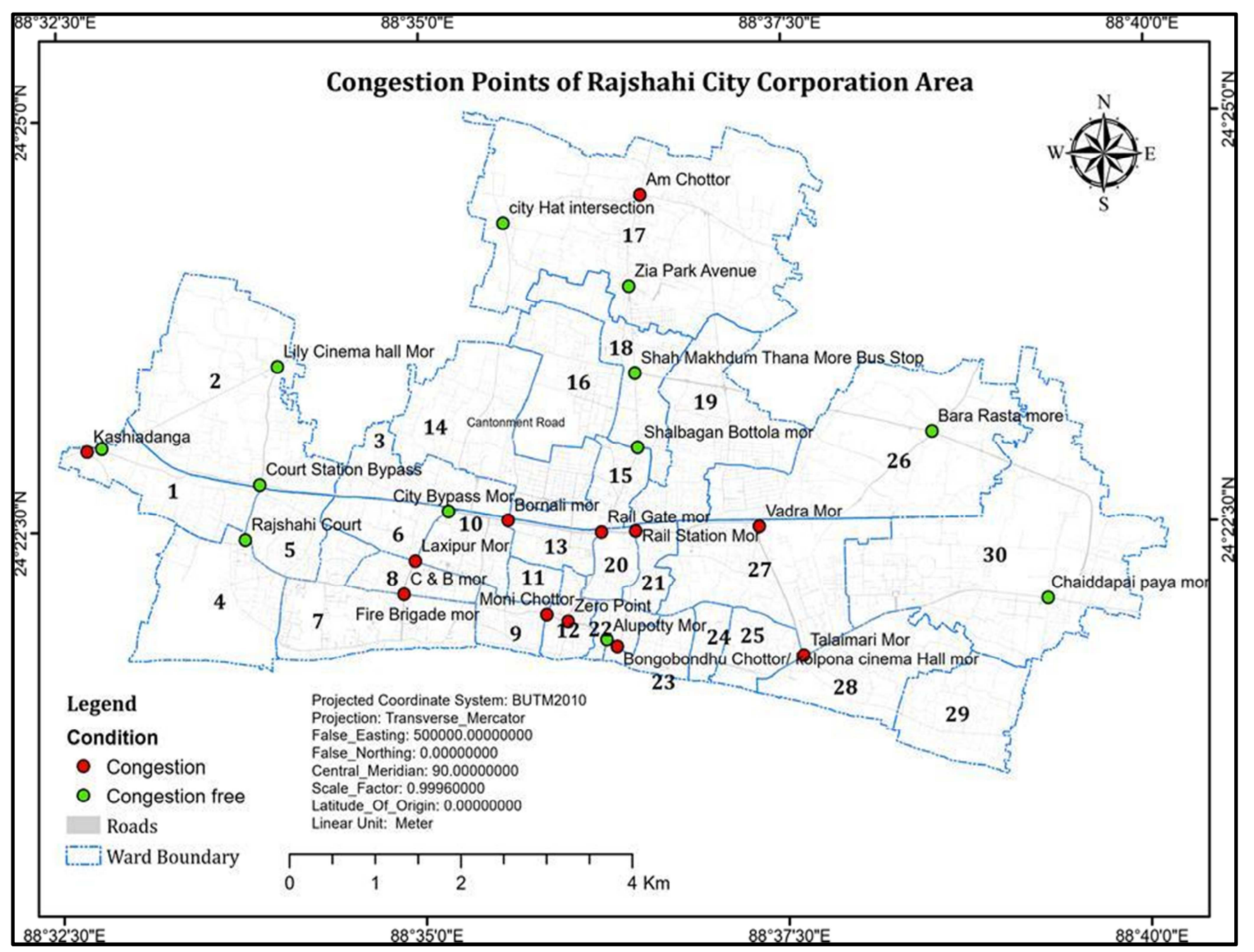

Figure 1. Congestion Points of Rajshahi City Corporation.

\subsection{Existing Problem Characteristics}

Rajshahi metropolitan city has traditionally served by a wide variety of transport modes. The major transportation system in Rajshahi city is developed with diversified vehicular types. These modes can be broadly classified into two groups, motorized transport (bus, mini-bus, truck, car, 
auto-rickshaw, auto-tempo, motorcycle, etc.) and nonmotorized transports (viz. rickshaw, rickshaw van, bicycle, pushcart, etc.). These diversified modes of transport use the same road space at the same time, which results in high congestion in some major intersections and causes a higher level of operational disorder (Appendix A1). Moreover, the transportation system among the city is good compared with the width of roads. There are no intra bus transits services within the city. Rickshaw and easy bikes are only modes of public transport. Most of the roads are much wider for traffic movement without any congestion but the stacking autorickshaws and easy bikes create congestion and complexities for traffic movements at the intersections. The growth of these slow-moving vehicles in Rajshahi has created many problems. As well as, parking of these vehicles at major intersection points is one of the worst issues [5]. The parking on the street covers most of the carriageway length in maximum times [6]. It is becoming a crucial issue in managing the transportation system since it affects the overall accessibility of a city Lack of regulation enforcement, lack of public awareness, improper traffic management are also responsible for traffic congestion in these intersections and $\mathrm{CBD}$ areas [7].

\subsection{Major Shares of Vehicular Traffics}

According to a recent analysis of RCC (Rajshahi City Corporation) major shares of vehicular traffics are autorickshaw (18.80\%), rickshaw (17.20\%), motorcycle $(17.20 \%)$, bi-cycle $(17.20 \%)$, truck $(10.20 \%)$, bus $(9.80 \%)$ and car $(2.80 \%)$. As well as the annual average growth rate of these traffics is motorized (8.50\%), auto-rickshaw (12.30\%), motorcycle (12.60\%), truck (5.30\%) and car (5.70\%) [8].

According to this statistic, it is clear that the major shares of traffic are publicly used transports such as- auto-rickshaw, rickshaw, motorcycle and bicycle. Basically, middle and lower-income people used these types of transport to reach their purposive destination every day. Which occupies most of the road spaces. As a result, sometimes traffic flows face troubles.

So, the upcoming future of the transportation sector in Rajshahi city is going to an uncertain complexity through the increasing population and rapidly growing motorized traffic which will affect the efficiency and effectiveness of the transport systems.

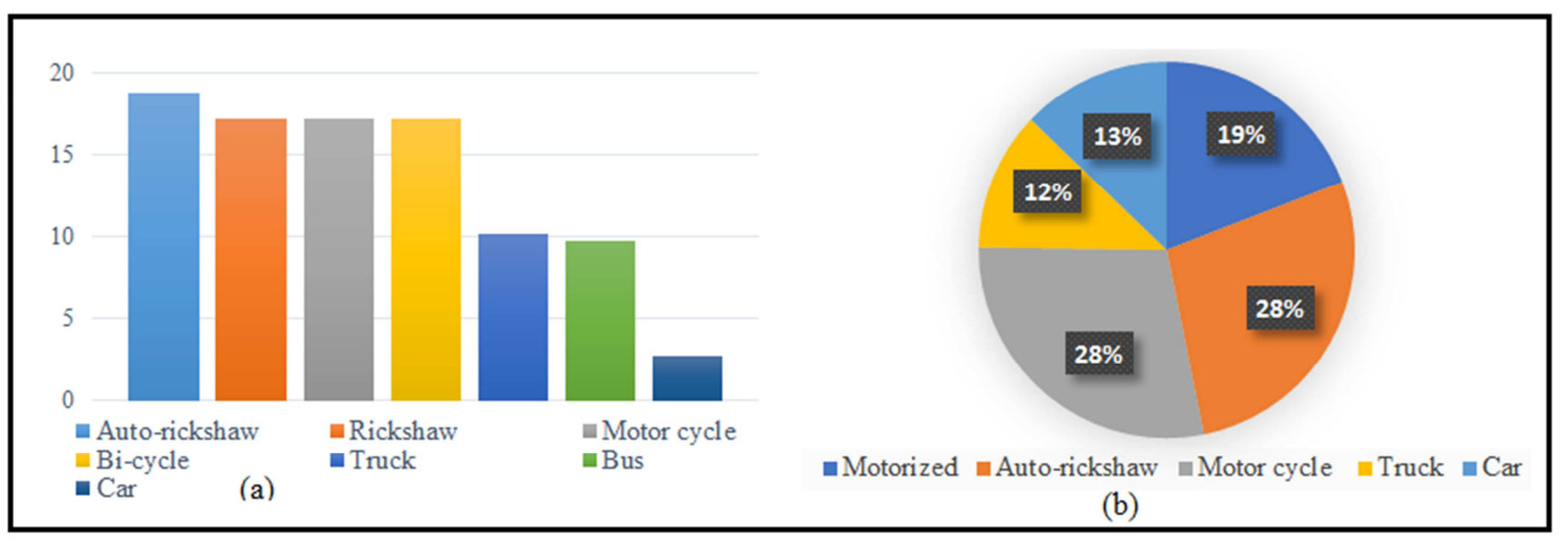

Figure 2. Shares of Vehicular Traffics in Rajshahi City; (a) Major Shares of Vehicular Traffics; (b) Annual Average Growth Rate of These Traffics.

\section{Bus Rapid Transit (BRT) as a Solution for Rajshahi}

A BRT plan basically an integrated system that adapts attributes of bus transit, focuses on major areas such asmarket areas, CBD areas, major employment centers, emphasize speed and reliability according to road width, effective and efficient urban transportation system $[9,10]$. To resolve the complexities and cope up with the transportation needs and demands of the public, public transport should be incorporated in the traffic sector of Rajshahi. Which is mandatory for improving the transportation system's quality. According to the existing land-use scenario and transportation conditions, BRT is the best option for Rajshahi to address the mass transit facility with relative advantages such as- fluency in traffic movements, uncongested traffic system, save of times and money, etc. [11].

BRT (Bus Rapid Transit) includes route planning and management to integrate urban centers and suburban that foster economic development and pedestrian-friendly transit [12]. Which make sure the flexibility and efficiency of bus transit. Developing countries with vast population sizes are gradually picking this option for the high transit-dependent populations and their financial resources to make an effective and efficient even a sustainable transportation system [8]. 


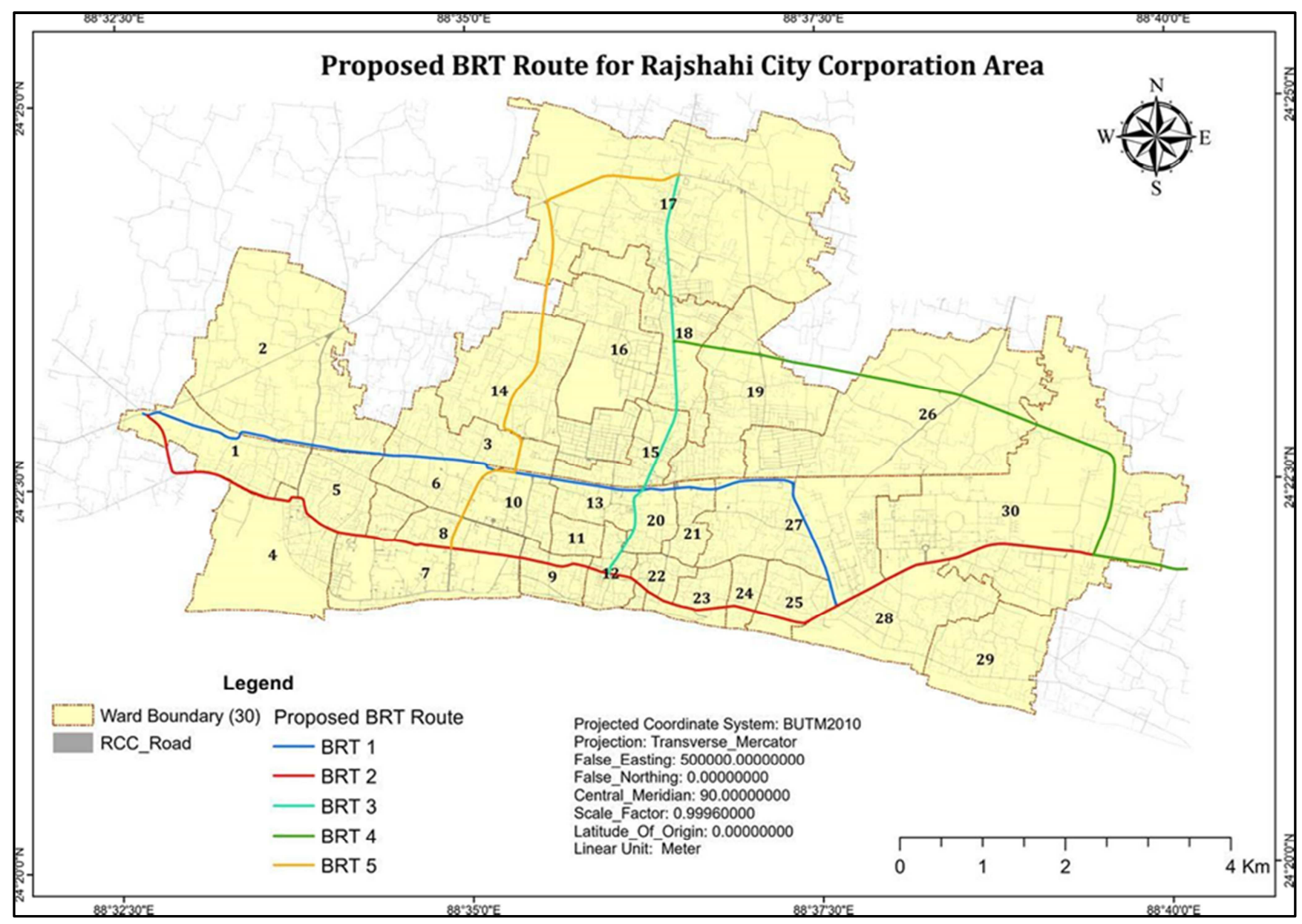

Figure 3. Propose BRT Route for Rajshahi City Corporation Area.

\subsection{Planning BRT for Rajshahi City}

Planning for a Bus Rapid Transit requires a realistic assessment of demands, benefits and impacts. The objective to develop BRT for Rajshahi is to -

a) Identifying the possible public bus transit route for Rajshahi city corporation.

b) Define the area coverage by the public bus transit and bus stoppage points.

c) Which will help to achieve attractive and reliable BRT services, serve public transportation demands, provide sustainable transport facility for future, relate long term development plans and ensure reasonable transportation cost.

Through the BRT planning process, some of the major key factors included. Such as-

a) Land use consideration: the intensity and growth prospects of activity centers, urban growth and expansion, $\mathrm{CBD}$ areas, major intersections, location of major employment centers, residential areas in relation to potential BRT routes and the peripheral areas.

b) Road network: connectivity of arterial, collector and local roads among the city, road width continuity, road conditions, capacity, congestion areas and opportunities for bus bays.

c) Bus operations: projected bus transit within the city, location of bus stops, reliability, operating speeds based on road width and condition.

Towards a better and effective public transport route, the first and most important aspect is to design an efficient and effective route network [13]. So, the proposed route design for Rajshahi BRT is prepared bellow following some general guidelines. Such as-

a) Proposed BRT-1: Running way generally connecting the city centers with outlying residential and commercial areas. This ensures connectivity of the peripheral area with the city centers and serves large residential catchments. Such as some of the peripheral area of the western and eastern part of Rajshahi city as Kashiadanga, Chaiddapai, Baro Rasatar Mor has connectivity with the center area such as Railgate, Bornali, Station Mor, Vadra, etc.

b) Proposed BRT-2: Running way serves and penetrates major CBD and market areas like Court Area, Zero Point, Shaheb Bazar, Railgate Mor, Vadra Mor and Laxmipur Mor which ensure the CBD distribution and neighborhood collection.

c) Proposed BRT-3: Running way ensures connectivity of the northern part of Rajshahi city such as City Hat Mor, Aam Chattar Area, Shah Mokdum, etc. with the city centers and also serves large residential catchments as 
each of the bus stops covers 200-meter radius areas.

d) Proposed BRT-4: Running way to ensure effective downtown passenger distribution facility such as the peripheral area Chaiddapai, Baro Rasatar Mor, etc.

e) Proposed BRT-5: Running way to ensure effective downtown passengers distribution facility such as the peripheral area such as City Hat Intersection, City Bypass Mor, Laxipur Mor, C\&B Mor and Fire Brigade Mor.

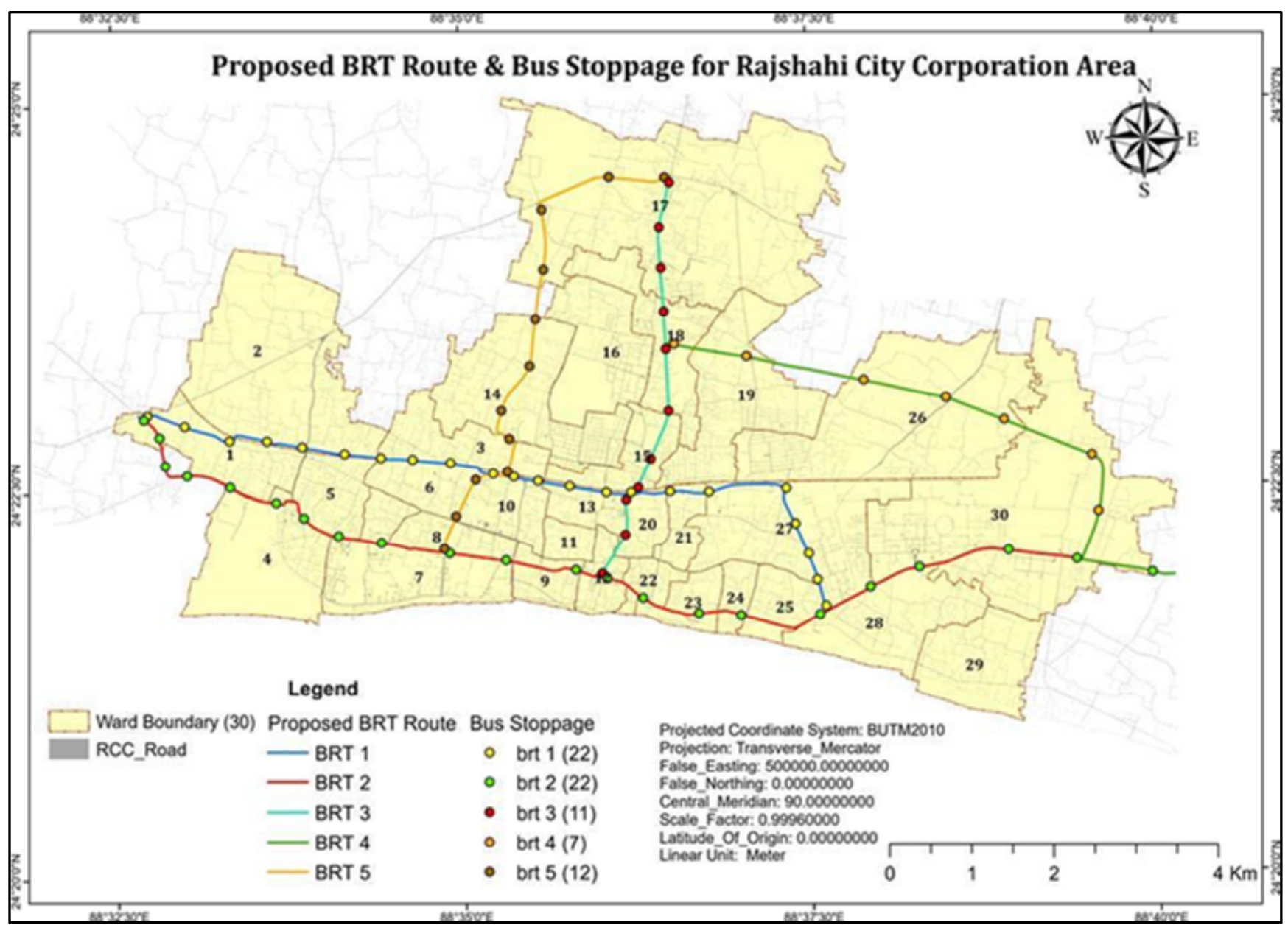

Figure 4. Proposed BRT Route \& Bus Stoppage for Rajshahi City Corporation Area.

\subsection{Concern Issues in Designing a BRT}

It found that in the case of developing citywide BRT systems always have some barriers to the creation given on the contextual differences, the different sizes, and the different level of development of the city [14]. For achieving a sustainable Bus Rapid Transit in Rajshahi it is obvious to aware of some issues that need to be concerned about. In Rajshahi, it is seen that there are some kinds of traffic operational hazards like operational disorder traffic management, lack of proper planning and control which diminish the efficiency and effectiveness of the existing transport systems considerably.

\subsubsection{Traffic Engineering}

The traffic engineering design required for BRT running ways varies with the type and location of BRT running ways. In Rajshahi, the road design follows the traffic engineering rules rather than any other city in Bangladesh. In our proposed Bus Rapid Transit, the design will be included (a) curb adjustments incorporate with the changes in roadway geometry and pavement markings; (b) curb parking and loading controls; (c) left- and right-turn controls; (d) and traffic signal controls including BRT priorities.

\subsubsection{Stops and Stations}

Bus stops, stations and associated facilities create the interface between passengers and the BRT system. The stoppage of the BRT should be convenient, comfortable, safe, and accessible to passengers with disabilities. These key concepts of BRT station follow some guidelines. Such as:

a) Bus stoppage should provide a full range of amenities including shelters, passenger information, telephones, lighting, and security provisions.

b) It should provide a consistent pattern of station location, configuration, and design.

c) To provide convenient transfers between two stations (like in a consistently built-up area), the distance between stops optimizes at around 450 meters. 
According to BRT guidelines, the optimal station spacing, the average distance between stations should not be below 300 meters or exceed 800 meters.

d) Preferable distance from the intersection, transit routes like the bus stoppage should be located at a minimum of 26 meters ( 85 feet), but ideally 40 meters (130 feet), from intersections to avoid delays [15].

e) The stoppage design help to facilitate the fare collection policies.

f) It should specially design for the access of customers who have disabilities. Size of station berths, platforms, and access facilities to serve the expected number of riders without overcrowding or spillback and to provide capacity for future growth, and to achieve reasonable levels of service.
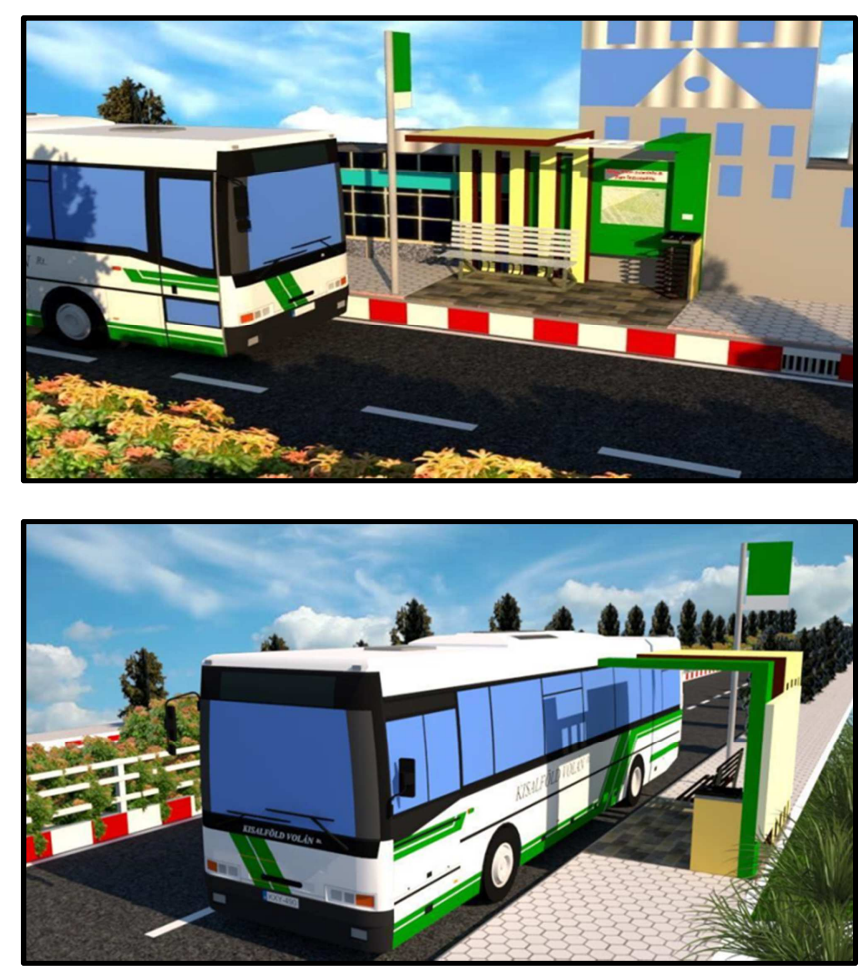

Figure 5. Design of a bus stop - at least five people can sit. Accessible routes and time schedule will available on the notice board.

\subsubsection{Vehicles}

The vehicles for public transit should be carefully selected and designed because of their impacts on travel times, service reliability, and operating/maintenance costs. The desired features of BRT vehicles include the following:

a) Vehicles should provide sufficient passenger capacity for expected users. They may be standard 40-foot or articulated 60 -foot buses for mainline service.

b) Vehicles should be easy to get on and off. This can be achieved by using low floor buses with floor heights 12 to 15 inches above street level and using wide, doublestream doors.

c) Internal vehicle design generally should maximize the number of people so that each bus can carry, rather than the number of seated passengers. This is less relevant for routes with long person trips.

\subsection{Achieving Sustainable Transportation System Through BRT in Rajshahi}

Improved traffic performance: through public

bus services unnecessary private vehicles will be decreased. As a result, the fluency in traffic movement will be ensured.

Improved connectivity: from the service area to all parts of the city where it increases availability and quality of mobility for the urban people.

Congestion reduction: shift into public transport lead to reductions of congestion in major intersections of center areas through system design, improved management and effective enforcement techniques.

Supporting special needs groups: Overall increases in mobility and specific improvements in availability and quality of mobility for the urban poor.

Pollution reduction: ensuring reduction of pollution such as environmental pollution, air pollution, sound pollution through reducing excessive unnecessary private vehicles.

Saving cost and time: relatively reasonable cost for the lower-income people and time-saving.

\section{Conclusion}

As the city is growing faster with a rapidly increasing population and uncontrolled traffic needs, the upcoming future of the transportation system in Rajshahi city is going to uncertain trouble. To resolve the complexities and cope up with the transportation needs and demands of the public, public transport should be incorporated in the traffic sector of Rajshahi. The context and the expected benefits of the Bus Rapid Transit (BRT) system towards achieving the sustainable public transport system in Rajshahi city are discussed in the paper. This is mandatory for improving the transportation system's quality with relative advantages such as- fluency in traffic movements, uncongested traffic system, save of times and money, etc.

\section{Acknowledgements}

The authors would like to thank Honorable Professor Dr. Shamim Mahabubul Haque Sir inspiring for this study as well as Emon Kabir Noyon Vaiya, Torit Chakraborty Dada, Shaharier Shawon Vaiya and Kamal Hossain Vaiya for guiding us. The authors would also like to thank the anonymous reviewers for their constructive and very insightful comments which significantly enhanced and improved this manuscript.

\section{Appendix}

Existing Scenario of Some Major Intersections of Rajshahi City 


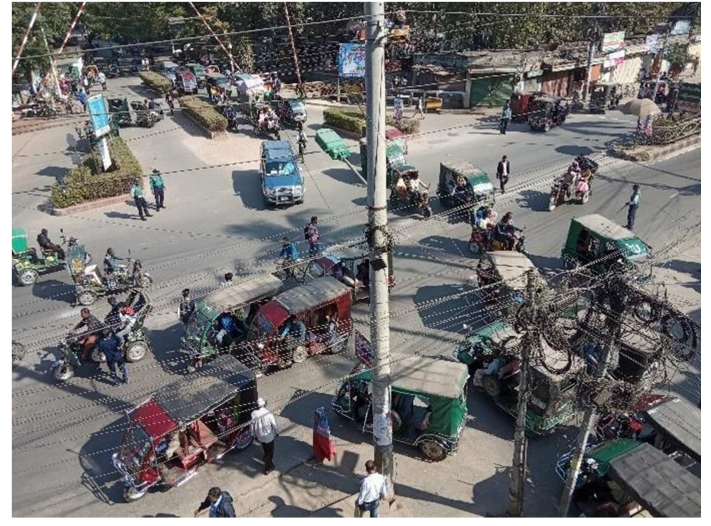

Figure 6. Bornali Mor.

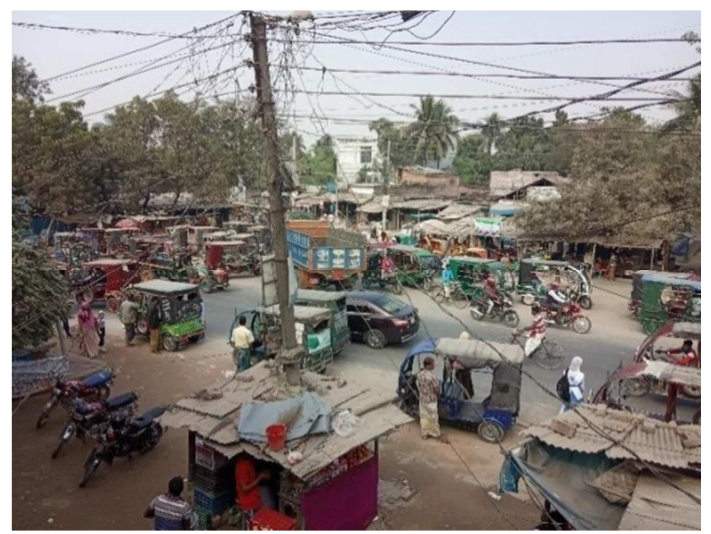

Figure 7. Kashiadanga Mor.

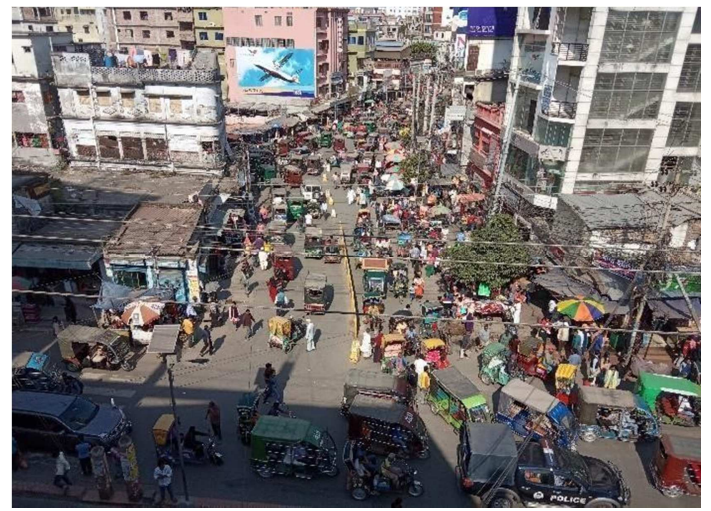

Figure 8. Shaheb Bazar Mor.

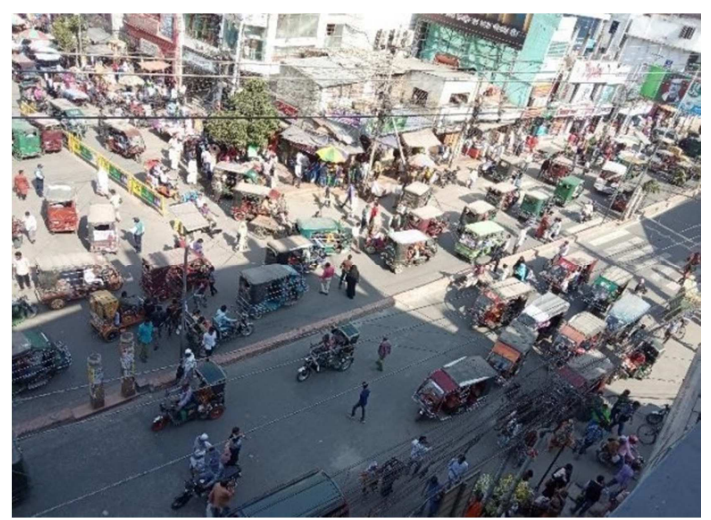

Figure 9. Zero Point Mor.

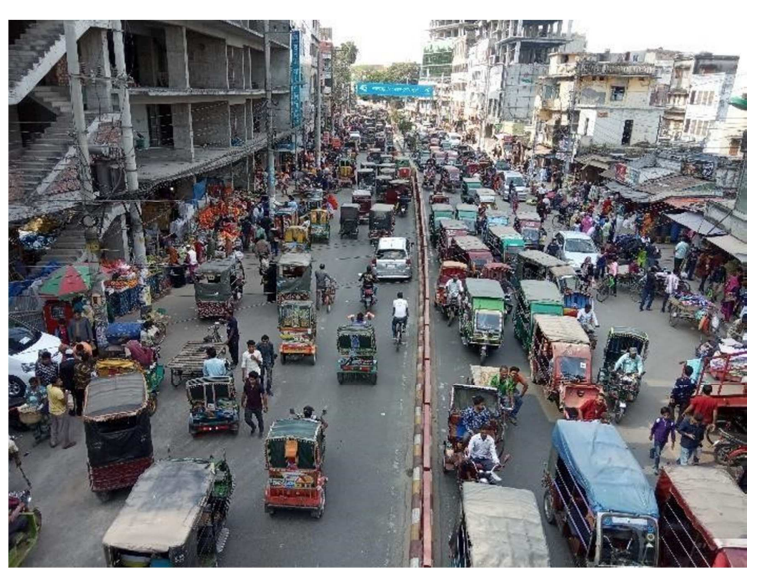

Figure 10. C\&B Mor Road.

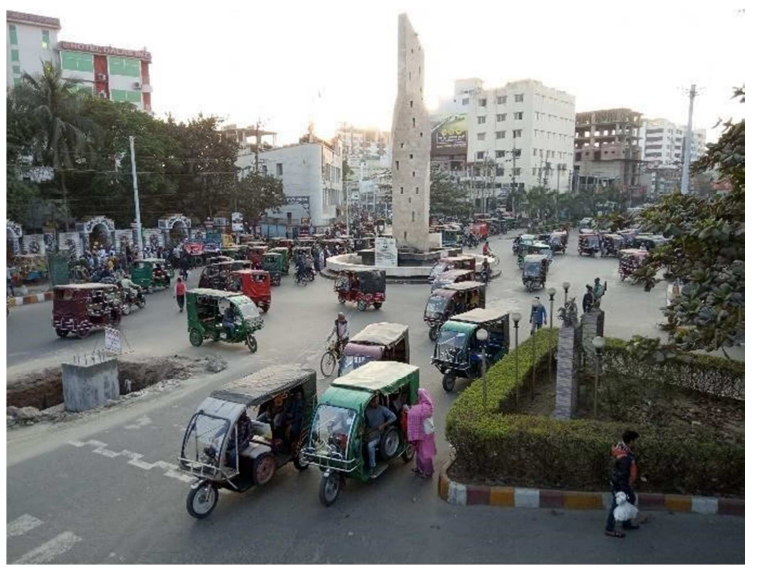

Figure 11. Railgate Mor.

\section{References}

[1] Bangladesh Bureau of Statistics (BBS) (2011) Community Report Rajshahi Zila 2012.

[2] Rajshahi, Bangladesh Population 1950-2019. (n.d.). Retrieved 11 December 2019 from

https://www.macrotrends.net/cities/20131/rajshahi/population ?fbclid=IwAR1qcEP3nn3zvvJJ

O0HdyIACIzGxcvAlBW5Sne79gOd82-XFRexggEAqd6U.

[3] Currie, G. (2018). Lies, damned lies, AVs, shared mobility, and urban transit futures. Journal of Public Transportation, 21 (1), 3 .

[4] Currie, G. J. J. o. P. T. (2006). Bus rapid transit in Australasia: Performance, lessons learned and futures. 9 (3), 1.

[5] Nahar, A., Chakma, R., Uddin, N., \& Das, A. (2018). Existing Situation of on Street Parking and Impacts on Effective Carriageway Width and V/C Ratio: A Case Study of Rajshahi City Corporation Area. International Journal of Science, Technology and Society, 6 (2), 33.

[6] Hasan, M., Ganguly, B., Chowdhury, S. R., Rahman, G. A., Sami, S., Sultana, J.,... \& Das, A. (2018). Analyzing the Impact of Land Use and Roadside Informal Activity on Transportation System: A Case Study in Rajshahi City Corporation, Bangladesh. 
[7] Rahman, F. I., \& Hasnat, A. (2018). Case Study on Transportation System in Rajshahi City, Bangladesh. Retrieved http://matjournals.in/index.php/JoTS/issue/view/474.

[8] Hoque, M. M., Barua, S., Ahsan, H., \& Alam, D. J. P. o. C. X. T. R. o. U. M. i. s. C. (2012). BRT in Metro Dhaka: towards achieving a sustainable urban public transport system. 1-11.

[9] Levinson, H., Zimmerman, S., Clinger, J., Rutherford, S., Smith, R. L., Cracknell, J., \& Soberman, R. J. T. R. B. o. t. N. A., Washington, DC. (2003). Trip report 90: Bus rapid transit, volume 1: Case studies in bus rapid transit.

[10] Levinson, H. S., Zimmerman, S., Clinger, J., Bast, J., Rutherford, S., \& Bruhn, E. (2003). Bus rapid transit, volume 2: Implementation guidelines.

[11] Ingvardson, J. B., \& Nielsen, O. A. (2018). Effects of new bus and rail rapid transit systems-an international review. Transport Reviews, 38 (1), 96-116.
[12] Schwanen, T., \& Ferbrache, F. (2017). Bibliography of research on bus rapid transit. Transport. EVTLnyMbY.

[13] Mortazavi, S. A. H., \& Akbarzadeh, M. (2017). A framework for measuring the spatial equity in the distribution of public transportation benefits. Journal of Public Transportation, 20 (1), 3 .

[14] Mallqui, Y. Y. C., \& Pojani, D. (2017). Barriers to successful Bus Rapid Transit expansion: Developed cities versus developing megacities. Case studies on transport policy, 5 (2), 254-266.

[15] The Scorecard. (n.d.). Retrieved from https://www.itdp.org/library/standards-and guides/thebusrapidtransit-standard/thescorecard/?fbclid=IwAR3ZArMDT9bfuZhO0FhA_N3MXDx vdLSaDbptbMwM4fLvwRfkrR 